\title{
Dysregulated luminal bacterial antigen-specific T-cell responses and antigen-presenting cell function in HLA-B27 transgenic rats with chronic colitis
}

Bi-Feng Qian, ${ }^{1}$ Susan L.

Tonkonogy, ${ }^{2}$ Frank Hoentjen, ${ }^{1}$

Levinus A. Dieleman ${ }^{1}$ and

R. Balfour Sartor ${ }^{1,3}$

${ }^{1}$ Center for Gastrointestinal Biology and Disease, Department of Medicine, University of North Carolina, Chapel Hill, NC, ${ }^{2}$ College of Veterinary Medicine, and ${ }^{3}$ Department of Microbiology and Immunology, North Carolina State University, Raleigh, NC, USA doi:10.1111/j.1365-2567.2005.02206.x Received 15 October 2004; revised 18 April 2005; accepted 4 May 2005.

Correspondence: Dr R. Balfour Sartor, Center for Gastrointestinal Biology and Disease, 7309 A Molecular Biology Research Building, CB \#7032, University of North Carolina at Chapel Hill, Chapel Hill, NC 27599, USA. Email: rbs@med.unc.edu Senior author: R. Balfour Sartor

\begin{abstract}
Summary
HLA-B27/ $\beta 2$ microglobulin transgenic (TG) rats spontaneously develop T-cell-mediated colitis when colonized with normal commensal bacteria, but remain disease-free under germ-free conditions. We investigated regulation of in vitro T-cell responses to enteric bacterial components. Bacterial lysates prepared from the caecal contents of specific pathogen-free (SPF) rats stimulated interferon- $\gamma($ IFN $-\gamma)$ production by TG but not non-TG mesenteric lymph node (MLN) cells. In contrast, essentially equivalent amounts of interleukin-10 (IL-10) were produced by TG and non-TG cells. However, when cells from MLNs of non-TG rats were cocultured with TG MLN cells, no suppression of IFN- $\gamma$ production was noted. Both non-TG and TG antigen-presenting cells (APC) pulsed with caecal bacterial lysate were able to induce IFN- $\gamma$ production by TG $\mathrm{CD}^{+}$ cells, although non-TG APC were more efficient than TG APC. Interestingly, the addition of exogenous IL-10 inhibited non-TG APC but not TG APC stimulation of IFN- $\gamma$ production by cocultured TG $\mathrm{CD}^{+}$lymphocytes. Conversely, in the presence of exogenous IFN- $\gamma$, production of IL-10 was significantly lower in the supernatants of TG compared to nonTG APC cultures. We conclude that commensal luminal bacterial components induce exaggerated in vitro IFN- $\gamma$ responses in HLA-B27 TG T cells, which may in turn inhibit the production of regulatory molecules, such as IL-10. Alterations in the production of IFN- $\gamma$, and in responses to this cytokine, as well as possible resistance of TG cells to suppressive regulation could together contribute to the development of chronic colitis in TG rats.
\end{abstract}

Keywords: antigen-presenting cells; $\mathrm{CD}^{+} \mathrm{T}$ lymphocytes; enteric bacterial antigens; HLA-B27 transgenic rats

\section{Introduction}

Transgenic (TG) rats expressing high levels of human HLA-B27 and $\beta_{2}$-microglobulin $\left(\mathrm{h} \beta_{2} \mathrm{~m}\right)$ spontaneously develop chronic immune-mediated colitis resembling, both clinically and histologically, human inflammatory bowel disease. ${ }^{1,2}$ These disease manifestations require commensal gut microflora. Rats raised in a germ-free (sterile) environment show no evidence of inflammation. ${ }^{3}$ However, these animals develop colitis within 1 month of being transferred to specific pathogen-free (SPF) housing conditions. ${ }^{4,5}$ Bacteroides vulgatus has been shown to preferentially stimulate colitis in gnotobiotic HLA-B27 TG rats. ${ }^{4,5}$

Host genetic susceptibility is important to the development of chronic intestinal inflammation. In the HLA-B27 TG rat model, lines that express lower levels of HLA-B27 and $\mathrm{h} \beta_{2} \mathrm{~m}$ and non-transgenic (non-TG) rats colonized in the same SPF conditions as disease-prone TG rats remain healthy. ${ }^{1,6}$ However, inflammation can be passively transferred to these disease-resistant rats by transplantation of bone marrow from the disease-prone lines. ${ }^{7}$ In contrast,

Abbreviations: STAT3, signal transducer and activator of transcription 3. 
non-TG bone marrow engraftment results in prompt disease amelioration in lethally irradiated TG recipients that have advanced colitis. ${ }^{7}$

As observed with many animal models of chronic intestinal inflammation, colitis in HLA-B27 TG rats seems to be mediated by Th1-dominated immune responses as evidenced by the production of interferon- $\gamma($ IFN- $\gamma)$ and tumour necrosis factor (TNF). ${ }^{8}$ The loss of tolerance to normally occurring non-pathogenic intestinal bacteria in genetically susceptible hosts can be the result of one or a combination of the following mechanisms: (1) an overly aggressive effector cell response, (2) inadequate regulatory cell development or function, or (3) impaired responses to regulatory signals. It has been shown that colitis in HLA-B27 TG rats is dependent on bone marrow-derived HLA-B27-expressing non-T lymphocytes, probably macrophages or dendritic cells. Elegant transfer experiments by Breban and colleagues have demonstrated that the presence of donor-derived $\mathrm{B} 27^{\text {bright }} \mathrm{CD} 4^{\text {dim }}$ cells with monocyte-macrophage morphology and expression of CD11b and CD11c correlates with the development and progression of colitis in the non-TG recipients. ${ }^{7}$ However, $\mathrm{T}$ lymphocytes are also essential for disease expression. Colitis does not develop in congenitally athymic nude TG rats, but can be initiated by T-cell reconstitution. ${ }^{9}$ In this regard, $\mathrm{CD}^{+} \mathrm{T}$ cells are reported to be more efficient than $\mathrm{CD} 8^{+}$cells in transferring disease.

While the precise mechanism by which the HLA-B27 molecule mediates disease development has not yet been identified, HLA-B27 molecules can form homodimers in addition to conventional $\beta_{2} \mathrm{~m}$-associated heterodimers that bind and present peptide antigens. ${ }^{10,11}$ Moreover, a recent report shows that HLA-B27 homodimers are capable of binding to a class of cell membrane molecules called paired immunoglobulin-like receptors (PIRs) that are expressed by subpopulations of macrophages, dendritic cells and $\mathrm{B}$ cells but not $\mathrm{T}$ cells. ${ }^{12}$ These intriguing observations may explain the susceptibility of HLA-B27 TG rats to development of chronic inflammation. For example, B27 homodimer binding to PIRs induces both TNF and nitric oxide production, which could in turn establish a cytokine environment that would favour IFN- $\gamma$ production by activated $\mathrm{T}$ cells. In addition, the role of commensal bacterial components may be to induce increased expression of PIRs by cell types that would provide high levels of proinflammatory molecules after B27 homodimer-mediated activation. ${ }^{13}$

Nevertheless, the relative roles of accessory cells and $\mathrm{T}$ lymphocytes in the inflammatory response and the possibility that $\mathrm{T}$ cells in inflamed hosts have altered responses to proinflammatory and regulatory signals remain to be clarified. In this study, we compared the lymphoid cell populations from mesenteric lymph nodes (MLNs), large intestinal epithelium and large intestinal lamina propria in HLA-B27 TG rats with severe colitis with their non-TG littermates, and investigated antigenpresenting cell (APC) and T-cell function by evaluating in vitro cytokine responses to physiological enteric bacterial stimuli. The differential response to proinflammatory and suppressive regulation in non-TG and TG cells was also analysed. Our results suggest that the maintenance of colitis in TG rats is the result, at least in part, of an inadequate response of accessory cells to regulatory signals.

\section{Materials and methods}

\section{Animals}

TG rats of the 33-3 line on an inbred F344 background bearing 55 copies of the HLA-B27 gene and 66 copies of the $\mathrm{h} \beta_{2} \mathrm{~m}$ gene, originally obtained from Dr Joel D. Taurog (Southwestern Medical School, Dallas, TX), and non-TG littermates were kept in a SPF environment. Offspring were generated by mating TG females with nonTG males and were genotyped for the HLA-B27 transgene by polymerase chain reaction (PCR) analysis of DNA from tail clippings. The expression of HLA-B27 on TG cells was confirmed by flow cytometry.

SPF TG rats with established colitis and non-TG littermates of mixed sexes, aged 4-6 months were used throughout. The investigation was approved by Institutional Animal Care and Use Committees, the University of North Carolina at Chapel Hill, and North Carolina State University.

\section{Preparation of caecal bacterial lysate}

Caecal bacterial lysate was prepared directly from the caecal contents of SPF non-TG rats according to a protocol described by Cong et al. ${ }^{14}$ Briefly, caecal contents from several non-TG rats were solubilized, digested with DNAse, and then homogenized using $0 \cdot 1-\mathrm{mm}$ glass beads in a mini-bead beater (Biospec Products, Bartlesville, OK). The supernatant collected was filter-sterilized through a $0 \cdot 45-\mu \mathrm{m}$ filter after centrifugation and the sterility was confirmed by aerobic and anaerobic culturing. The protein concentration was determined using a standard assay (Biorad Laboratories, Hercules, CA). Optimal concentrations of lysates for cell activation varied between 50 and $200 \mu \mathrm{g} / \mathrm{ml}$ in different batches and therefore, in some experiments, the results obtained using the optimal concentration only are shown.

\section{Preparation of single cell suspensions and enriched lymphoid cell subpopulations}

Mesenteric lymph node cells. MLN cell suspensions were prepared by gentle teasing of MLNs obtained from HLAB27 TG and non-TG rats. 
MLN APC were prepared by rabbit complement-mediated lysis of $\mathrm{T}$ cells bound by immunoglobulin $\mathrm{M}$ (IgM) anti-rat CD3 monoclonal antibody (Clone 1F4, PharMingen, San Jose, CA). The resulting population contained less than $4 \% \mathrm{CD}^{+}$or $\mathrm{CD}^{+}$cells for the non-TG rats and $8 \%$ for the TG rats. Neither the $\mathrm{CD}^{+}$cells nor the $\mathrm{CD}^{+}$cells that remained expressed surface CD3, probably because of the molecule internalization.

For the $\mathrm{CD}^{+}$T-lymphocyte purification the MLN $\mathrm{CD}^{+} \mathrm{T}$ lymphocytes were enriched by depletion of $\mathrm{B}$ cells and $\mathrm{CD}^{+}$cells using magnetic beads conjugated with either anti-CD45RA (Clone OX-33) or anti-CD8 $\alpha$ (Clone G38) monoclonal antibodies in a magnetic antibody cell sorting system (MACS) (Miltenyi, Auburn, CA). The purity (mean $\pm \mathrm{SE}$ ) of the enriched $\mathrm{CD} 4^{+} \mathrm{T}$-lymphocyte population, from a total of 28 TG and 19 non-TG T-cell enrichment experiments, as confirmed by flow cytometry, was $96 \pm 0 \cdot 2 \%$ and $96 \pm 0 \cdot 3 \%$ for TG and non-TG MLN cells, respectively.

Intestinal lymphocytes. Large intestinal lymphocytes from both epithelial (IEL) and lamina propria (LPL) compartments of HLA-B27 TG and non-TG rats were isolated according to a modification of published procedures. ${ }^{15}$ In brief, the intestines were opened longitudinally, washed, and cut into small pieces. The intestinal epithelial layer was selectively detached from the mucosa by treatment with $1 \mathrm{~mm}$ dithiothreitol in a shaker water-bath at room temperature for $20 \mathrm{~min}$, followed by vortexing for $4 \mathrm{~min}$. The supernatant, which contained IEL and epithelial cells, was collected.

The residual tissues were then incubated twice in a shaker water-bath at $37^{\circ}$ for $40 \mathrm{~min}$ with a mixture of collagenase type II and IV $(290 \mathrm{U} / \mathrm{ml})$ (Sigma Chemical, St Louis, MO), and then disrupted mechanically. A stainless steel grid (60 mesh) was used to remove large particulate material. Single cells passing through the grid were harvested.

IEL and LPL fractions were further purified by Percoll (Amersham Pharmacia Biotech Inc, Uppsala, Sweden) density gradient centrifugation. Lymphocytes enriched in the interface between 70 and $40 \%$ Percoll were recovered.

Viability of the isolated MLN and intestinal cells was $\geq 95 \%$ as determined by Trypan blue exclusion.

\section{Flow cytometry}

Freshly isolated unseparated MLN cells, MLN APC, MLN $\mathrm{CD}^{+}$enriched cells as well as large intestinal IEL and LPL $\left(2 \times 10^{5}\right.$ to $\left.5 \times 10^{5} / 50 \mu \mathrm{l}\right)$ were analysed on a flow cytometer (FACScan, Becton Dickinson, San Jose, CA) using CELLQUEST ${ }^{\mathrm{TM}}$.

The following fluorochrome-labelled or unlabelled reagents were used. For identification of HLA-B27-expressing cells, we used cell culture supernatant from the murine hybridoma, designated ME-1 (American Type Culture Collection, Rockville, MD), followed by fluorescein isothiocyanate (FITC)-labelled goat anti-mouse $\operatorname{IgG}(\gamma)$ antibody (Southern Biotechnology, Birmingham, AL). T cells were detected by FITC-conjugated anti-Pan T-cell monoclonal antibody (Clone OX-52, PharMingen). In additional experiments, phycoerythrin (PE)-conjugated anti-CD3 monoclonal antibody (Clone G4·18, PharMingen) was also used for the detection of cells expressing CD3. B cells were detected by PE-conjugated antiCD45RA monoclonal antibody (Clone OX-33, PharMingen). Surface immunoglobulin-expressing $\mathrm{B}$ cells were identified by FITC-labelled goat anti-rat $\operatorname{IgG}(\mathrm{H}+\mathrm{L})$ antibody (Kirkegaard \& Perry Laboratories, Gaithersburg, $\mathrm{MD}) . \mathrm{CD}^{+}$and $\mathrm{CD}^{+}$cells were identified using PE-conjugated anti-CD4 (Clone W3/25) and FITC-labelled antiCD8 (Clone OX-8) monoclonal antibodies (Caltag, Burlingame, CA), respectively. To compare CD25 expression on $\mathrm{CD}^{+}$cells of MLN, large intestinal IEL, and large intestinal LPL from non-TG and TG rats, monoclonal antibody against CD25 (Clone OX-39, PharMingen) was used.

Cells incubated with FITC- or PE-conjugated isotype standard from the same species and at the same concentrations served as negative controls.

\section{Unseparated cell cultures}

Unseparated MLN cells $\left(4 \times 10^{5}\right)$ in triplicate and large intestinal lymphocytes $\left(1 \times 10^{5}\right)$ in duplicates were cultured in 96-well flat-bottom microplates (Costar, Corning, NY) in $0.2 \mathrm{ml}$ complete medium (RPMI-1640 supplemented with $5 \%$ heat inactivated fetal calf serum, $2 \mathrm{~mm}$ L-glutamine, $1 \mathrm{~mm}$ sodium pyruvate, $50 \mu \mathrm{M}$ 2-mecaptoethanol, and $50 \mu \mathrm{g} / \mathrm{ml}$ gentamicin) and stimulated with different concentrations of caecal bacterial lysate for $6-72 \mathrm{hr}$.

In selected experiments, unfractionated non-TG and TG MLN cells were cultured in different ratios with a total number of $4 \times 10^{5}$ per well and stimulated with caecal bacterial lysate for 3 days.

\section{Cocultures of APC and $C D 4^{+}$T lymphocytes}

MLN APC were pulsed with caecal bacterial lysate or with keyhole limpet haemocyanin (KLH: Pierce, Rockford, IL), an unrelated antigen, in complete culture medium overnight with or without the addition of exogenous recombinant rat IFN- $\gamma$ (BD Biosciences PharMingen) or interleukin (IL)-10 (R \& D Systems, Minneapolis, MN).

The cells were then washed twice to remove soluble bacterial antigens and other components. They were cultured either alone at $3 \times 10^{5}$ cells per well in a final volume of $0.2 \mathrm{ml}$ in flat-bottom 96 -well plates, or with 
additional exogenous IFN- $\gamma$ or IL-10, or with $2 \times 10^{5}$ freshly isolated MLN CD4 $4^{+} \mathrm{T}$ cells in a humidified incubator at $37^{\circ}$ in $7 \% \mathrm{CO}_{2}$. In selected experiments, $2 \times 10^{5} \mathrm{CD}^{+}$-enriched non-TG and TG MLN cells were mixed in different ratios and then cocultured with antigen-pulsed APC. The APC concentration was determined by culturing different numbers of non-TG APC $\left(1 \times 10^{5}\right.$ to $5 \times 10^{5}$ /well) with a constant number of $\mathrm{TG} \mathrm{CD} 4^{+}$ cells $\left(2 \times 10^{5} /\right.$ well $)$. The results indicated that non-TG APC at $3 \times 10^{5}$ cells per well or more induced optimal IFN- $\gamma$ responses. Triplicate supernatants were harvested after 3 or 6 days. Supernatants collected on day 6 contained similar amounts of IFN- $\gamma$ and IL-10 to supernatants collected on day 3. Therefore, analyses of IFN- $\gamma$ and IL-10 detected on day 3 after culture initiation are shown.

\section{Enzyme-linked immunosorbent assay (ELISA)}

IFN- $\gamma$ and IL-10 in cell culture supernatants were measured in triplicate by ELISA using unlabelled capture antibodies and biotin-labelled detection antibodies, followed by horseradish peroxidase-labelled streptavidin (PharMingen).

For IFN- $\gamma$, we used unlabelled rabbit polyclonal antiIFN- $\gamma$ antibody and biotin-labelled monoclonal antiIFN- $\gamma$ antibody (Clone DB-1) (Biosource International, Camarillo, CA). For IL-10 we used unlabelled monoclonal anti-rat IL-10 antibody (Clone A5-7) and biotin-labelled monoclonal anti-rat IL-10 antibody (Clone A5-6) (PharMingen). The concentration was determined by comparison to a standard curve generated using recombinant rat IFN- $\gamma$ or IL-10 (PharMingen).

\section{Western blot analysis}

Freshly isolated unseparated MLN cells or APC were cultured either alone in complete medium or with recombinant rat IL-10 $(10 \mathrm{ng} / \mathrm{ml})$ or caecal bacterial lysate $(50 \mu \mathrm{g} / \mathrm{ml})$ for $30 \mathrm{~min}$ or $2 \mathrm{hr}$ in six-well plates (Costar), collected and lysed in $1 \times$ Laemmli buffer. In selected experiments, the cells were cultured in medium alone or stimulated with caecal bacterial lysate for $24 \mathrm{hr}$ before the treatment with exogenous IL-10. The protein concentration was measured using a Bio-Rad quantification assay (Bio-Rad Laboratories, Hercules, CA). Fifteen micrograms of protein extracts were subjected to electrophoresis on $13 \%$ sodium dodecyl sulphate-polyacrylamide gels and transferred to nitrocellulose membranes. Polyclonal antibodies against phospho-signal transducer and activator of transcription 3 (STAT3) or STAT3 (Santa Cruz Biotechnology, Santa Cruz, CA) were used at a $1: 1000$ dilution. The specific immunoreactive proteins were detected using the enhanced chemiluminescence kit (ECL, Perkin Elmer).

\section{Statistical analysis}

Results from flow cytometric analyses and ELISA are expressed as mean \pm SEM. The probability of zero difference between groups was judged by two-tailed Student $t$-test. A $P$-value less than 0.05 was considered to be statistically significant.

\section{Results}

Evaluation of mucosal lymphoid cell populations and cytokine response to luminal commensal bacterial antigen stimulation in TG versus non-TG rats

SPF TG rats uniformly develop severe colitis that is evident at 4-6 months of age. In contrast, none of the nonTG rats, which were housed either in the same cages as, or in adjacent cages to, their TG littermates, showed signs of inflammation. The caecum and colon of TG rats were markedly enlarged and thickened and contained more lymphoid cells and higher numbers of $\mathrm{CD}^{+}$cells (Fig. 1a) in the epithelium and lamina propria compared to nonTG rats. The MLNs were also grossly increased in size with a significantly higher number of cells. ${ }^{8}$ MLN, IEL and LPL of TG rats all contained elevated proportions of $\mathrm{T}$ cells, $\mathrm{CD}^{+} \mathrm{T}$ cells and $\mathrm{CD} 25^{+} \mathrm{CD} 4^{+} \mathrm{T}$ cells compared with non-TG rats (Fig. 1a,b). Unfractionated TG MLN cells, IEL and LPL all produce IFN- $\gamma$ after in vitro stimulation with caecal bacterial lysate (Fig. 1c). The IFN- $\gamma$ response was measured over a lysate concentration range between 0 and $200 \mu \mathrm{g} / \mathrm{ml}$ and was dose-dependent in TG cells. In contrast, IFN- $\gamma$ responses in non-TG cells to caecal bacterial lysate were not higher than to medium alone. Consistent with our previous observations ${ }^{8}$, MLN cells from TG and non-TG rats produced comparable amounts of IL-10 in response to caecal bacterial lysate. Only low levels of IL-10 were detected in IEL and LPL (data not shown).

\section{$\mathrm{CD}^{+}$MLN T lymphocytes from TG rats but} not from non-TG rats produce high levels of IFN- $\gamma$ in response to luminal bacterial lysate-pulsed APC

Since MLN cells, IEL and LPL are similar in having elevated proportions of $\mathrm{CD}^{+}{ }^{+} \mathrm{T}$ cells and each cell population responded to stimulation with bacterial components, MLN cells were used as representative cells of the mucosa-associated immune system for our subsequent study of the mechanisms of the immune-mediated disease in HLA-B27 TG rats.

We investigated the relative roles of $\mathrm{APC}$ and $\mathrm{T}$ lymphocytes in the inflammatory responses in TG rats. Caecal bacterial lysate-pulsed APC from both non-TG and TG MLN induced significantly increased IFN- $\gamma$ 

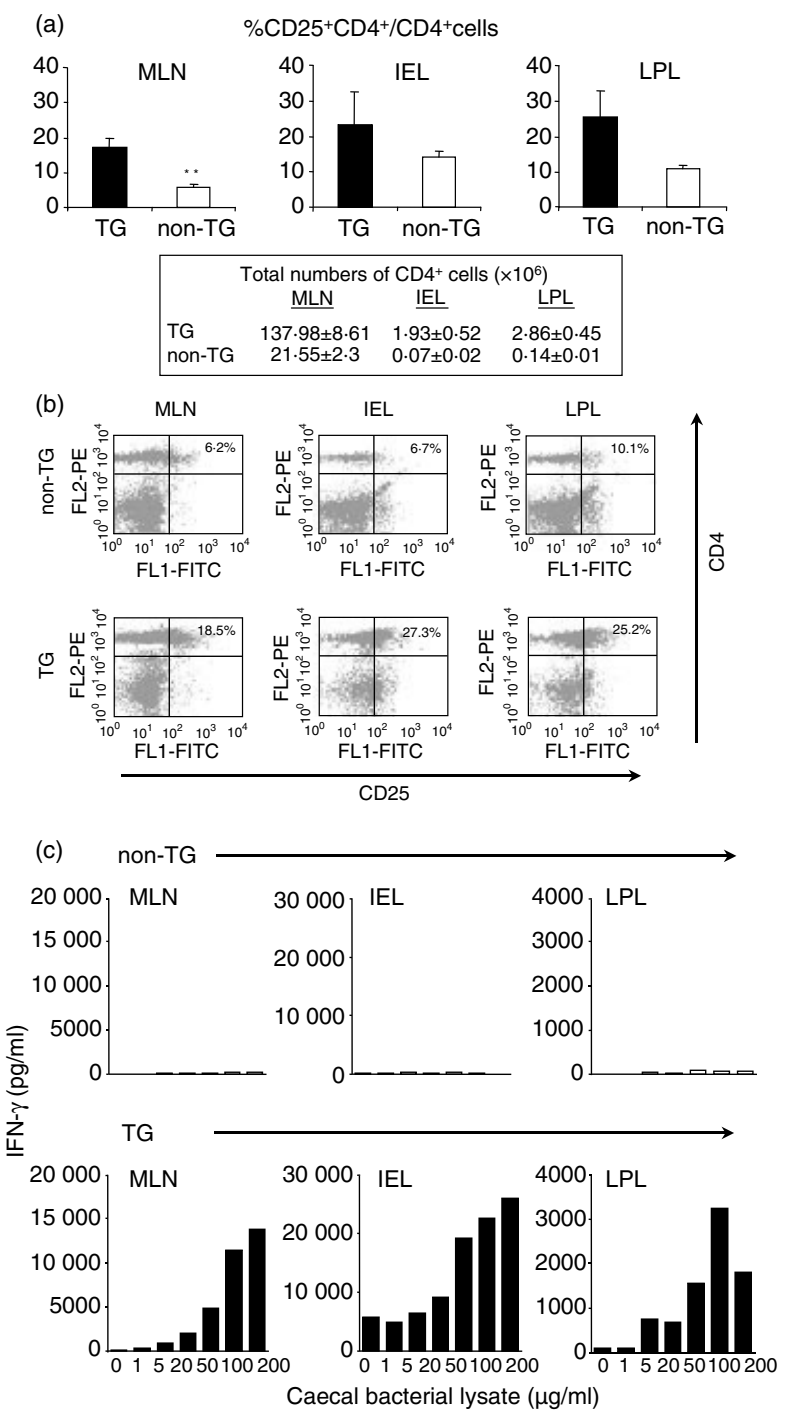

Figure 1. Comparison of cell subpopulations and interferon- $\gamma$ (IFN- $\gamma$ ) production by mesenteric lymph node (MLN), colonic intraepithelial (IEL) and lamina propria (LPL) cells from specific pathogen free HLAB27 transgenic (TG) and non-TG rats. The percentage (a) of CD25 expressing cells in the $\mathrm{CD}^{+}$T-cell population is presented as mean \pm SEM from four independent experiments. Statistically significant differences between TG and non-TG rats are denoted by asterisks $\left({ }^{*} P<0 \cdot 01\right)$. The mean \pm SEM of the total numbers of $\mathrm{CD} 4^{+}$cells is indicated. Dot plots (b) show CD25 expression on $\mathrm{CD} 4^{+} \mathrm{T}$ cells of a representative experiment. The percentage of $\mathrm{CD} 25$ expressing $\mathrm{CD} 4^{+}$ cells is given. IFN- $\gamma$ levels (c) in supernatants of MLN, IEL and LPL cell cultures from HLA-B27 TG and non-TG rats are shown. Cells were stimulated with various concentrations of caecal bacterial lysate $(\mu \mathrm{g} / \mathrm{ml})$ for $48 \mathrm{hr}$. Data shown are representative of two independent experiments.

production by $\mathrm{TG} \mathrm{CD} 4^{+}$lymphocytes in a dose-dependent fashion (Figs 2 and 3). Surprisingly, caecal bacterial lysate-pulsed TG APC were less effective than non-TG $\mathrm{APC}$ in activating $\mathrm{TG} \mathrm{CD}^{+} \mathrm{T}$ cells in vitro and induced lower amounts of IFN- $\gamma$ (Fig. 2). IFN- $\gamma$ was barely detect-

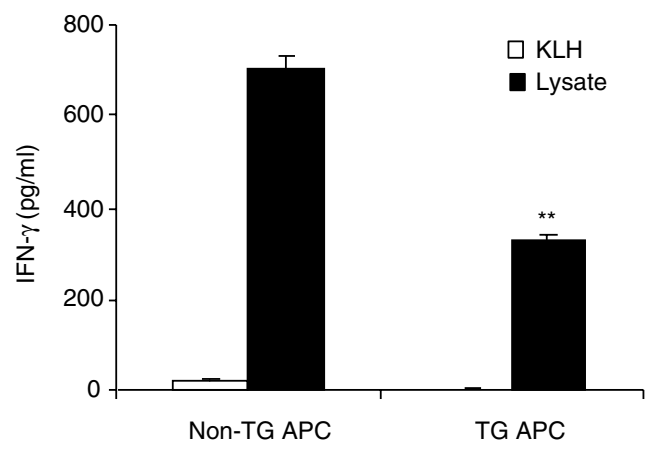

Figure 2. Interferon- $\gamma$ (IFN- $\gamma$ ) production by mesenteric lymph node $\mathrm{CD}^{+} \mathrm{T}$ lymphocytes from specific pathogen-free HLA-B27 transgenic (TG) rats cultured with antigen-presenting cells (APC) that were pulsed with either caecal bacterial lysate $(100 \mu \mathrm{g} / \mathrm{ml})$ or an unrelated antigen, KLH. Co-culture supernatants were harvested on day 3. ELISA values $(\mathrm{pg} / \mathrm{ml})$ represent mean \pm SEM and are representative of 15 independent experiments. Statistically significant differences between caecal bacterial lysate-pulsed TG and non-TG APC in inducing IFN- $\gamma$ production by TG $\mathrm{CD}^{+}$cells are denoted by asterisks $\left({ }^{*} P<0 \cdot 01\right)$.

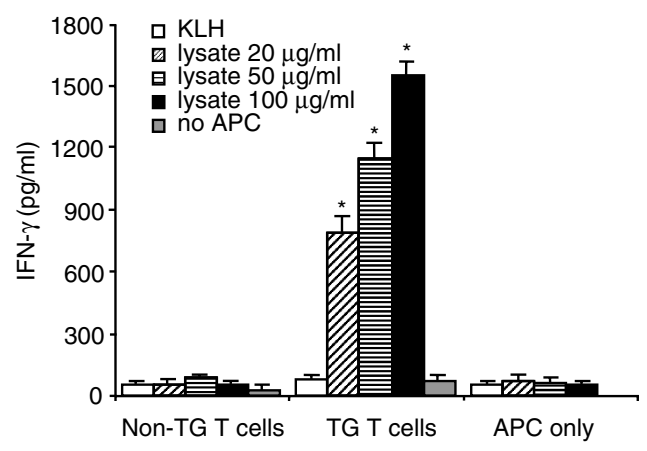

Figure 3. Interferon- $\gamma$ (IFN- $\gamma$ ) production by mesenteric lymph node $\mathrm{CD}^{+} \mathrm{T}$ lymphocytes from specific pathogen free HLA-B27 transgenic (TG) or non-TG rats cocultured with non-TG antigenpresenting cells (APC) pulsed with different concentrations of caecal bacterial lysate or an unrelated antigen, KLH $(100 \mu \mathrm{g} / \mathrm{ml})$. Supernatants were harvested on day 3 . IFN- $\gamma$ amounts $(\mathrm{pg} / \mathrm{ml})$ represent mean \pm SEM and are representative of 19 independent experiments. Statistically significant differences between KLH and caecal bacterial lysate-pulsed APC in inducing IFN- $\gamma$ production are denoted by asterisks $\left({ }^{\star} P<0 \cdot 001\right)$.

able in cultures of TG $\mathrm{CD}^{+}$cells stimulated with $\mathrm{KLH}-$ pulsed APC or cultured in the absence of APC. Supernatants of non-TG $\mathrm{CD}^{+}{ }^{+} \mathrm{T}$ cells stimulated with caecal lysate-pulsed APC and supernatants of caecal bacterial lysate-pulsed APC cultured without $\mathrm{CD} 4^{+} \mathrm{T}$ cells also contained very low amounts of IFN- $\gamma$. Therefore, the IFN- $\gamma$ response observed depends on in vitro activation of APC by bacterial components and/or presentation of bacterial antigens by APC to activated $\mathrm{TG} \mathrm{CD}^{+}{ }^{+} \mathrm{T}$ cells 
(Fig. 3). These results indicate that prior in vivo activation of $\mathrm{CD}^{+}$MLN cells is required for the detection of IFN- $\gamma$ response in vitro.

Luminal bacterial lysate-stimulated non-TG MLN cells are unable to regulate IFN- $\gamma$ production by cocultured TG cells

To determine if non-TG MLN contain regulatory cells capable of suppressing IFN- $\gamma$ production, we mixed nonTG and TG MLN cells in different ratios and analysed the influence of cocultured non-TG cells on IFN- $\gamma$ production. As shown in Fig. 4, unfractionated non-TG MLN cells cocultured with TG MLN cells did not have the ability to inhibit IFN- $\gamma$ production by TG cells. Similarly, when non-TG $\mathrm{CD}^{+}$cells were added to cocultures of caecal bacterial lysate-pulsed non-TG APC together with TG $\mathrm{CD}^{+}$cells, the IFN- $\gamma$ response was not reduced (Fig. 5). These results indicate that either regulatory $\mathrm{CD} 4{ }^{+}$MLN cells were not present in non-TG rats or that TG $\mathrm{CD}^{+}$cells were unresponsive to regulatory signals from non-TG MLN cells.

\section{Addition of exogenous IL-10 to caecal bacterial lysate-pulsed non-TG but not TG APC significantly suppresses IFN $-\gamma$ production by TG $\mathrm{CD} 4^{+} \mathrm{T}$ cells}

The exaggerated IFN- $\gamma$ response in TG rats could be the result of decreased responsiveness of TG cells to suppressive molecules such as IL-10. To address this issue, we first evaluated IFN- $\gamma$ production in supernatants of unseparated TG MLN cells stimulated with caecal bacterial lysate in the presence or absence of exogenous recombinant rat IL-10 using concentrations that approximated

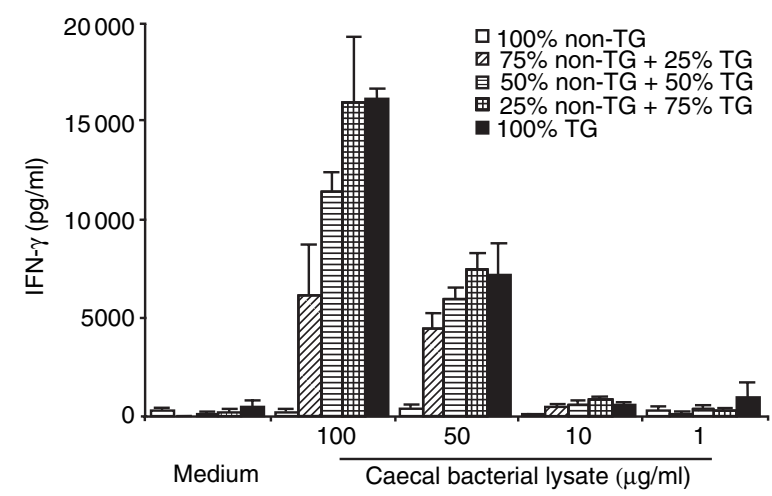

Figure 4. Interferon- $\gamma$ (IFN- $\gamma$ ) levels in specific pathogen free HLAB27 transgenic (TG) and non-TG mesenteric lymph node cell cocultures. Unseparated cells from non-TG and TG rats were mixed in different ratios and stimulated with various concentrations of caecal bacterial lysate. Supernatants were harvested on day 3. IFN- $\gamma$ amounts $(\mathrm{pg} / \mathrm{ml})$ represent mean \pm SEM. Cells cultured alone in medium served as a control.

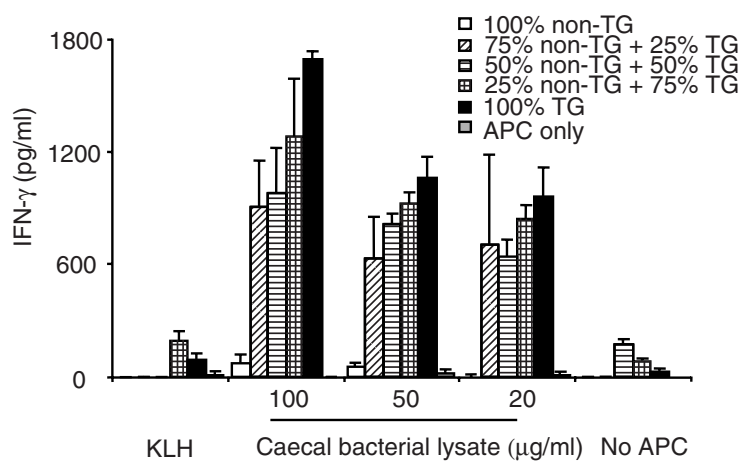

Figure 5. Interferon- $\gamma($ IFN- $\gamma$ ) levels in specific pathogen-free HLAB27 transgenic (TG) and non- $\mathrm{TG} \mathrm{CD}^{+}{ }^{+} \mathrm{T}$-cell cocultures in response to caecal bacterial lysate-pulsed non-TG antigen-presenting cells (APC). $\mathrm{CD}^{+}$-enriched mesenteric lymph node cells from non-TG and TG rats were mixed in different ratios and stimulated with nonTG APC pulsed with various concentrations of caecal bacterial lysate. Supernatants were harvested on day 3 . ELISA values $(\mathrm{pg} / \mathrm{ml})$ represent mean \pm SEM. Controls included $\mathrm{CD}^{+}$cells cultured with an unrelated antigen KLH-pulsed APC or cultured alone in medium. Since the two controls showed similar results, the medium control is not shown.

the levels seen after in vitro stimulation of MLN cells with caecal bacterial lysate. ${ }^{8}$ No effect on IFN- $\gamma$ production was observed (data not shown). In further studies addressing the response to IL-10, APC from TG or non-TG rats were pulsed with caecal bacterial lysate in the presence or absence of exogenous IL-10 at various concentrations and then, after being washed, the APC were cocultured with TG $\mathrm{CD}^{+} \mathrm{T}$ lymphocytes with or without the addition of IL-10. The IFN- $\gamma$ levels in the cocultures that contained either non-TG APC or TG APC were compared.

We found that TG APC were defective in their response to exogenous IL-10. Administration of IL-10 to non-TG APC during the pulsing or to the APC/CD4 $4^{+}$ lymphocyte cocultures reduced the IFN $-\gamma$ production by TG CD4 ${ }^{+}$cells (Fig. 6). Non-TG APC responded to all three doses of IL-10 that we added either during the pulsing or during the 3-day coculture; there was no additive effect of exogenous IL-10 provided during the pulsing and during the coculture. In contrast, no reproducible inhibition of IFN- $\gamma$ was noted in cocultures containing TG APC (data not shown). Since IL-10 functions primarily through the STAT3 pathway, we investigated STAT3 phosphorylation in non-TG and TG cells stimulated with IL-10 or caecal bacterial lysate. ${ }^{16}$ As shown in Fig. 7, low levels of phosphorylated STAT3 were detected in TG but not non-TG cells, collected after a 30-minute culture in medium without additional stimulation. Both exogenous IL-10, at $30 \mathrm{~min}$ after culture initiation, and caecal bacterial lysate, after $2 \mathrm{hr}$, activated STAT3 in APC (Fig. 7) and unseparated MLN cells (data not shown) from both TG and non-TG rats. Non-TG and TG cells expressed 


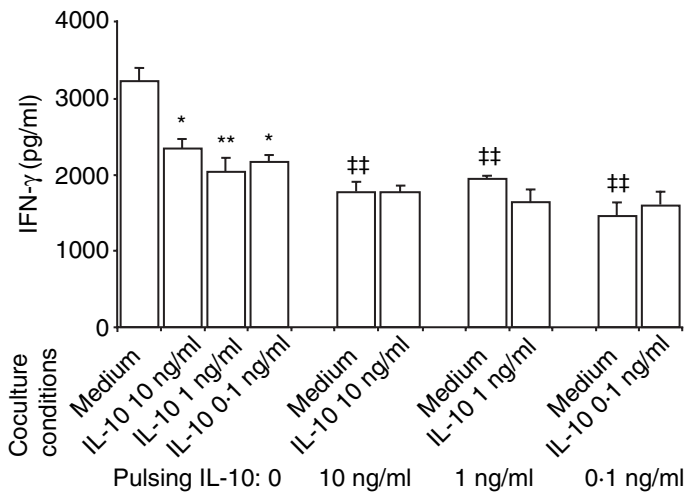

Figure 6. Effect of exogenous interleukin-10 (IL-10) on interferon- $\gamma$ (IFN- $\gamma$ ) production by transgenic (TG) $\mathrm{CD}^{+} \mathrm{T}$ cells induced by activated non-TG antigen-presenting cells (APC). Specific pathogenfree non-TG APC were pulsed overnight with $50 \mu \mathrm{g} / \mathrm{ml}$ of caecal bacterial lysate in the presence or absence of recombinant rat IL-10 $(10,1$ or $0 \cdot 1 \mathrm{ng} / \mathrm{ml})$. The APC were washed and then additional IL-10 $(10,1$ or $0 \cdot 1 \mathrm{ng} / \mathrm{ml})$ or medium alone was added for the duration of the 3-day coculture of APC with TG $\mathrm{CD} 4^{+} \mathrm{T}$ lymphocytes. Supernatants were assayed by ELISA and IFN- $\gamma$-values represent mean \pm SEM of $\mathrm{pg} / \mathrm{ml}$. Results shown are representative of two independent experiments. Statistically significant differences between the APC treated with or without the exogenous IL-10 during the pulsing $(\dagger P<0.01)$ or the 3 -day coculture $\left({ }^{\star} P<0.05,{ }^{*} P<0.01\right)$ in inducing IFN- $\gamma$ production by TG $\mathrm{CD} 4^{+}$cells are denoted.

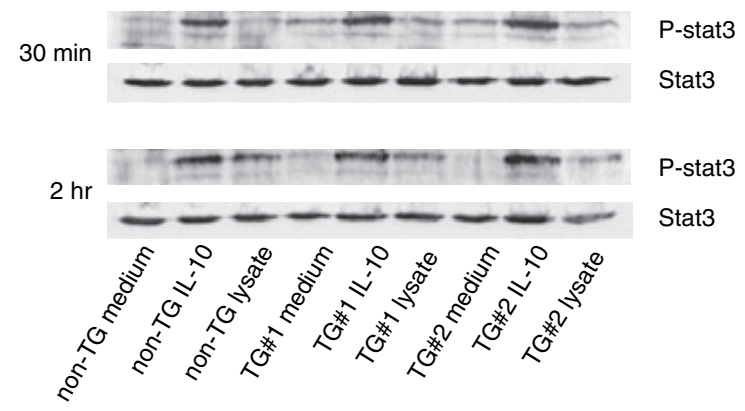

Figure 7. Phosphorylation of STAT3 in specific pathogen-free HLA-B27 transgenic (TG) and non-TG mesenteric lymph node antigen-presenting cells. Cells were cultured in medium alone or with recombinant rat IL-10 $(10 \mathrm{ng} / \mathrm{ml})$ or with caecal bacterial lysate at $50 \mu \mathrm{g} / \mathrm{ml}$ for $30 \mathrm{~min}$ or $2 \mathrm{hr}$. Western blot analysis was performed for phospho-STAT3 and STAT3. The results are representative of two independent experiments.

equivalent amounts of phosphorylated STAT3 after the induction by IL-10 (at $30 \mathrm{~min}$ and at $2 \mathrm{hr}$ ) or by caecal bacterial lysate (at $2 \mathrm{hr}$ ). Pretreatment with caecal bacterial lysate or culturing the cells without stimulation for $24 \mathrm{hr}$ did not result in detectable differences in STAT3 phosphorylation between TG and non-TG MLN cells (data not shown). These results indicate that STAT3 activation does not appear to be compromised in TG cells and that non-TG and TG cells recognize IL-10.

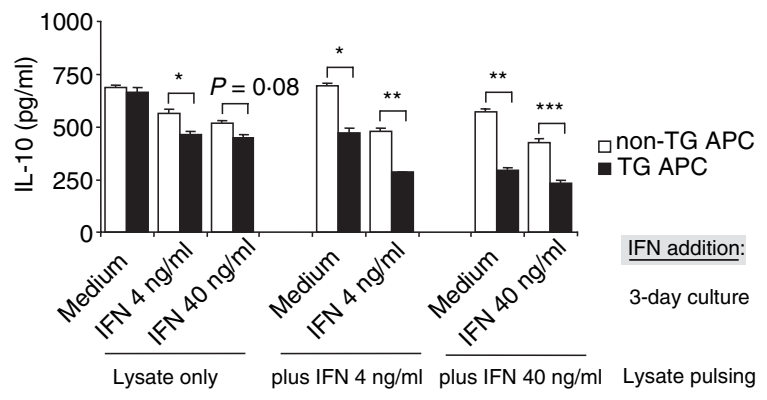

Figure 8. Effect of exogenous interferon- $\gamma$ (IFN- $\gamma$ ) on interleukin-10 (IL-10) production by caecal bacterial lysate-pulsed mesenteric lymph node antigen-presenting cells (APC). Specific pathogen-free transgenic (TG) and non-TG APC were pulsed overnight with $100 \mu \mathrm{g} / \mathrm{ml}$ of caecal bacterial lysate with or without recombinant rat IFN- $\gamma$ ( 40 or $4 \mathrm{ng} / \mathrm{ml}$ ). The cells were washed and then additional rat IFN- $\gamma$ (40 or $4 \mathrm{ng} / \mathrm{ml}$ ) was added for the duration of the 3-day culture. Supernatants were assayed by ELISA and IL-10 values represent mean \pm SEM of $\mathrm{pg} / \mathrm{ml}$. Results shown are representative of two independent experiments. It should be noted that exogenous IFN- $\gamma$ added to either non-TG or TG APC inhibited IL-10 production (compared to IL-10 in supernatants of cells stimulated with lysate only). Statistically significant differences between IL-10 produced by identically treated TG and non-TG cells are denoted by asterisks $\left({ }^{*} P<0.05,{ }^{* *} P<0.01,{ }^{* *} P<0.001\right)$.

\section{IFN- $\gamma$-mediated inhibition of IL-10 production is more pronounced in caecal bacterial lysate-pulsed TG compared to non-TG APC}

To explore how non-TG and TG IL-10 producing cells respond to proinflammatory signals, recombinant rat IFN- $\gamma$ at concentrations equivalent to those detected in unseparated TG MLN cell cultures or APC/TG $\mathrm{CD}^{+}$ lymphocyte cocultures was added to non-TG and TG APC during the overnight pulsing with caecal bacterial lysate. ${ }^{8}$ The pulsed cells were then washed as usual to remove non-engulfed caecal bacterial lysate and additional exogenous IFN- $\gamma$ was added for the duration of the 3-day cultures. Recombinant rat IFN- $\gamma$ added to both non-TG and TG APC consistently inhibited IL-10 production. However, the effect was much more pronounced on TG than non-TG cells at all concentrations of IFN- $\gamma$-tested (Fig. 8). Inhibition was maximal when exogenous IFN- $\gamma$ was present during the pulsing with caecal bacterial lysate as well as during the 3-day culture. As the amount of recombinant rat IFN- $\gamma$ added was increased, the secretion of IL-10 by APC from both TG and non-TG rats decreased (Fig. 8).

\section{Discussion}

In many animal models of chronic intestinal inflammation, including $\mathrm{IL}-2^{-1-}$, $\mathrm{IL}-10^{-1-}$, TGF- $\beta^{-/-}$and $\mathrm{A} 20^{-1-}$ mice, as well as in patients with inflammatory bowel diseases a dysregulated immune response to intestinal 
commensal microflora, reflected by either excessive responses to mucosal antigens or adjuvants or defective regulatory activity, seems to play a major role in the disease development. ${ }^{17,18}$ Colitis in most of these models is mediated by Th1 immune responses. This concept is further supported by the results of our present study using HLA-B27 TG rats, in which we show that $\mathrm{CD} 4^{+} \mathrm{T}$ cells of TG rats produce high amounts of IFN- $\gamma$ when cocultured with APC pulsed with caecal bacterial lysate. We compared the cell populations and cytokine production of MLN cells, colonic IEL and LPL in response to physiologically relevant lysates of luminal contents in SPF HLA-B27 TG rats with established colitis with those in normal nonTG rats. We show that HLA-B27 TG MLN, colonic IEL and LPL all have significantly increased amounts of total $\mathrm{T}$ cells, $\mathrm{CD} 4^{+} \mathrm{T}$ cells and $\mathrm{CD} 25^{+} \mathrm{CD} 4^{+} \mathrm{T}$ cells compared to non-TG littermates. Caecal bacterial lysate stimulates IFN- $\gamma$ production, in a similar dose-responsive pattern, by MLN cells, IEL and LPL from TG but not from nonTG rats. We therefore conclude that in vitro production of the proinflammatory cytokine IFN- $\gamma$ by mucosal lymphoid cells stimulated with caecal bacterial lysates corresponds to in vivo disease expression and that draining MLN cells are representative of the mucosa-associated immune system for our study of the mechanisms of the immune-mediated colitis in HLA-B27 TG rats.

APC process and present antigens to $\mathrm{T}$ lymphocytes, and secrete regulatory cytokines important for determining immune activation or immune tolerance. $\mathrm{CD} 4^{+}$ T lymphocytes can activate macrophages to increase phagocytosis and killing and also to produce cytokines that are essential for the generation of antibody-producing plasma cells and differentiation of cytolytic T cells. An important aspect of our study was to determine the relative roles of $\mathrm{APC}$ and $\mathrm{CD}^{+} \mathrm{T}$ lymphocytes in the inflammatory response in TG rats. We found that both TG and non-TG APC activated by caecal bacterial lysate can induce IFN- $\gamma$ production by $\mathrm{TG} \mathrm{CD} 4^{+} \mathrm{T}$ lymphocytes. Comparatively, non-TG APC have more potent stimulatory effects. The reasons for the apparent impaired ability of TG APC in vitro are unclear, but we have found in separate studies that the expression of the costimulatory molecules CD86 and major histocompatibility complex (MHC) class II are not efficiently up-regulated on TG APC as compared to non-TG APC after stimulation with caecal bacterial lysate (unpublished data included in a separate manuscript). Hacquard-Bouder et al. have recently identified a defect in the ability of dendritic cells from HLA-B27 TG rats to form conjugates with $\mathrm{T}$ cells, supporting an earlier report of defective allogeneic stimulation by dendritic cells expressing HLA-B27. ${ }^{19,20}$

Of potential relevance to immunoregulation, the IFN- $\gamma$ response in TG rats could be the result of (1) a failure to generate regulatory cells or molecules, (2) decreased responsiveness of TG cells to suppressive molecules such as IL-10, or (3) exaggerated inhibition of IL-10 production by IFN $-\gamma$. In the present study, we observed that the proportion of $\mathrm{CD} 4^{+} \mathrm{CD} 25^{+}$cells, a proposed subset of regulatory cells, was actually increased instead of reduced in TG rats with colonic inflammation and that the production of IL-10 was not significantly different between lysate-stimulated TG and non-TG MLN cells when equivalent numbers of IL-10-producing cells are evaluated. ${ }^{8,21}$ $\mathrm{CD} 25$, the $\alpha$-chain of the IL-2 receptor, is an activation marker that is increased in colitis. Furthermore, when we cocultured non-TG and TG MLN cells in different ratios, non-TG cells did not appear to regulate IFN- $\gamma$ production by TG cells. This suggests that regulatory $\mathrm{T}$ cells are either not present in non-TG MLN cell preparations or that activated $\mathrm{CD}^{+}{ }^{+} \mathrm{T}$ cells from TG rats do not appropriately respond to regulatory signals.

A compromised response to regulatory signals in TG rat APC was suggested by the addition of recombinant IL-10. IFN- $\gamma$ production by TG $\mathrm{CD} 4^{+}$MLN cells cocultured with caecal bacterial lysate-pulsed non-TG APC could be diminished but not eliminated by the addition of exogenous IL-10 in vitro during either the APC pulsing or coculture phases. In contrast, TG APC appeared to be less responsive to the inhibitory signals provided by IL-10. This defective response was not the result of a lack of recognition of IL-10 or proximal signalling responses, because STAT3 phosphorylation was similar in TG and non-TG APC stimulated with recombinant IL-10. The low steady-state level of phospho-STAT 3 before in vitro IL-10 stimulation in TG APC was most likely secondary to active colitis in TG rats, perhaps because of increased IL-6. ${ }^{4}$ These results strongly suggest that the endogenous production of IL-10 in non-TG rats and its suppressive role are important for the homeostasis of the mucosal immune system and that a possible defect in the cellular response to inhibitory signals may contribute to the development of colitis in TG rats.

Conversely, IL-10 production by TG APC was substantially reduced by administration of exogenous IFN- $\gamma$ during the pulsing and/or the 3-day culture, while much less inhibition was found in non-TG APC. The comparatively steady production of IL-10 in non-TG rats, even in the presence of a proinflammatory cytokine, may provide an important mechanism to restore tolerance to commensal bacteria and prevent damaging inflammatory responses after a transient stimulus.

IL-10 is a primary immunoregulatory cytokine, produced by a variety of different cell types and has a critical role in maintaining the balance between immune activation and immune tolerance. ${ }^{16}$ We have reported that $\mathrm{B}$ cells are the major source of IL-10 in in vitro cultures of rat MLN cells stimulated with caecal bacterial lysate. ${ }^{8}$ The development of colitis in IL-10-deficient mice demonstrates that IL-10 is essential in the control of gut inflammation. ${ }^{22}$ The importance of IL-10 was also 
highlighted by the findings that deleting CRF2-4, a member of the class II cytokine receptor family serving as a subunit of IL-10 receptor, or the selective disruption of STAT3, a protein associated with IL-10 signalling, in macrophages and neutrophils, leads to colitis in mice with a Th1-biased cytokine profile. ${ }^{23,24}$

The role of IL-10 in preventing experimental colitis is well documented. Administration of murine recombinant IL-10, although having no influence on disease expression, efficiently inhibited IFN- $\gamma$ mRNA expression in HLA-B27 TG rats with established colitis. ${ }^{25}$ In separate experiments, chronic enterocolitis and arthritis induced by bacterial cell wall polymers in Lewis rats were prevented by recombinant IL-10, although this treatment did not reverse active disease. ${ }^{26}$ In adoptive transfer models, the prevention of Th1-mediated colitis after cotransfer of IL-10-producing regulatory $\mathrm{T}$ cells was shown. ${ }^{27,28}$ However, this protection was not seen after cotransferring the same type of cells from IL-10-deficient mice and could be abrogated by the treatment with anti-IL-10 receptor antibody. ${ }^{27}$

A potentially fruitful avenue for future studies designed to evaluate the regulation of the immune response in HLA-B27 TG rats would be to investigate the role of the recently identified HLA-B27 homodimer in immunoregulation. Homodimers of HLA-B27 bind paired immunoglobulin-like receptor molecules (PIRs). ${ }^{12}$ Two functionally different forms of cell membrane PIRs have been identified. Ligation of PIR-A delivers an activating signal while binding of PIR-B is inhibitory. ${ }^{29}$ It has been reported that in MHC class I-deficient mice, PIR-B phosphorylation is greatly reduced. ${ }^{30} \mathrm{We}$ and others have found that HLA-B27 TG rats have a lower expression of rat MHC class I as compared to non-TG littermates. ${ }^{1}$ Therefore, it is possible that the potential for inhibition via PIR-B is reduced in TG rats. An understanding of the relationship between the function of these signalling molecules and development of chronic intestinal inflammation in the HLA-B27 TG rat model of colitis could shed new light on the mechanism of disease pathogenesis.

In summary, caecal bacterial lysate, a complex of physiologically relevant bacterial antigens and adjuvants, can incite an exaggerated in vitro IFN- $\gamma$ response in APCactivated $\mathrm{TG} \mathrm{CD}^{+} \mathrm{T}$ lymphocytes, which may in turn suppress the production of regulatory molecules, such as IL-10. Alterations in the production of IFN- $\gamma$, and in responses to this cytokine, as well as possible lack of recognition of regulatory signals by TG cells could be pivotal in the development of chronic colitis in HLA-B27 TG rats.

\section{Acknowledgements}

The authors thank Desmond McDonnell for technical assistance at the College of Veterinary Medicine, North
Carolina State University, Raleigh, and Drs Bo Liu and Feng Ling Li at the University of North Carolina at Chapel Hill for maintaining the SPF rat colony. These studies were supported by U.S. Public Health Service Grants NIH RO1 DK 40249 and P30 DK 34987.

\section{References}

1 Hammer RE, Maika SD, Richardson JA, Tang JP, Taurog JD. Spontaneous inflammatory disease in transgenic rats expressing HLA-B27 and human beta $2 \mathrm{~m}$. An animal model of HLA-B27associated human disorders. Cell 1990; 63:1099-112.

2 Sartor RB. Colitis in HLA-B27/beta 2 microglobulin transgenic rats. Int Rev Immunol 2000; 19:39-50.

3 Taurog JD, Richardson JA, Croft JT, Simmons WA, Zhou M, Fernandez-Sueiro JL, Balish E, Hammer RE. The germfree state prevents development of gut and joint inflammatory disease in HLA-B27 transgenic rats. J Exp Med 1994; 180:2359-64.

4 Rath HC, Herfarth HH, Ikeda JS et al. Normal luminal bacteria, especially Bacteroides species, mediate chronic colitis, gastritis, and arthritis in HLA-B27/human beta2 microglobulin transgenic rats. J Clin Invest 1996; 98:945-53.

5 Rath HC, Wilson KH, Sartor RB. Differential induction of colitis and gastritis in HLA-B27 transgenic rats selectively colonized with Bacteroides vulgatus or Escherichia coli. Infect Immun 1999; 67:2969-74.

6 Taurog JD, Maika SD, Simmons WA, Breban M, Hammer RE. Susceptibility to inflammatory disease in HLA-B27 transgenic rat lines correlates with the level of B27 expression. J Immunol 1993; 150:4168-78.

7 Breban M, Hammer RE, Richardson JA, Taurog JD. Transfer of the inflammatory disease of HLA-B27 transgenic rats by bone marrow engraftment. J Exp Med 1993; 178:1607-16.

8 Dieleman LA, Hoentjen F, Qian BF et al. Reduced ratio of protective versus proinflammatory cytokine responses to commensal bacteria in HLA-B27 transgenic rats. Clin Exp Immunol 2004; 136:30-9.

9 Breban M, Fernandez-Sueiro JL, Richardson JA, Hadavand RR, Maika SD, Hammer RE, Taurog JD. T cells, but not thymic exposure to HLA-B27, are required for the inflammatory disease of HLA-B27 transgenic rats. J Immunol 1996; 156:794803.

10 Antoniou AN, Ford S, Taurog JD, Butcher GW, Powis SJ. Formation of HLA-B27 homodimers and their relationship to assembly kinetics. J Biol Chem 2003; 279:8895-902.

11 Boyle LH, Hill Gaston JS. Breaking the rules. the unconventional recognition of HLA-B27 by CD4+ T lymphocytes as an insight into the pathogenesis of the spondyloarthropathies. Rheumatology (Oxford) 2003; 42:404-12.

12 Kollnberger S, Bird LA, Roddis M et al. HLA-B27 heavy chain homodimers are expressed in HLA-B27 transgenic rodent models of spondyloarthritis and are ligands for paired Ig-like receptors. J Immunol 2004; 173:1699-710.

13 Kubagawa H, Chen CC, Ho LH et al. Biochemical nature and cellular distribution of the paired immunoglobulin-like receptors, PIR-A and PIR-B. J Exp Med 1999; 189:309-18.

14 Cong Y, Brandwein SL, McCabe RP, Lazenby A, Birkenmeier $\mathrm{EH}$, Sundberg JP, Elson CO. CD4+ T cells reactive to enteric bacterial antigens in spontaneously colitic $\mathrm{C} 3 \mathrm{H} / \mathrm{HeJBir}$ mice: 
increased $\mathrm{T}$ helper cell type 1 response and ability to transfer disease. J Exp Med 1998; 187:855-64.

15 Qian BF, Zhou GQ, Hammarstrom ML, Danielsson A. Both substance $\mathrm{P}$ and its receptor are expressed in mouse intestinal T lymphocytes. Neuroendocrinology 2001; 73:358-68.

16 Moore KW, de Waal Malefyt R, Coffman RL, O'Garra A. Interleukin-10 and the interleukin-10 receptor. Annu Rev Immunol 2001; 19:683-765.

17 Sartor RB. Animal models of intestinal inflammation. In: Sartor, RB, Sandborn, WJ, eds. Kirsner's Inflammatory Bowel Diseases. Philadelphia: Elsevier 2004:120-37.

18 Wen Z, Fiocchi C. Inflammatory bowel disease: autoimmune or immune-mediated pathogenesis? Clin Dev Immunol 2004; 11:195-204.

19 Hacquard-Bouder C, Falgarone G, Bosquet A, Smaoui F, Monnet D, Ittah M, Breban M. Defective costimulatory function is a striking feature of antigen-presenting cells in an HLA-B27transgenic rat model of spondylarthropathy. Arthritis Rheum 2004; 50:1624-35.

20 Stagg AJ, Breban M, Hammer RE, Knight SC, Taurog JD. Defective dendritic cell (DC) function in a HLA-B27 transgenic rat model of spondyloarthropathy (SpA). Adv Exp Med Biol 1995; 378:557-9.

21 Singh B, Read S, Asseman C et al. Control of intestinal inflammation by regulatory T cells. Immunol Rev 2001; 182:190-200.

22 Kuhn R, Lohler J, Rennick D, Rajewsky K, Muller W. Interleukin-10-deficient mice develop chronic enterocolitis. Cell 1993; 75:263-74.
23 Spencer SD, Di Marco F, Hooley J et al. The orphan receptor CRF2-4 is an essential subunit of the interleukin 10 receptor. J Exp Med 1998; 187:571-8.

24 Takeda K, Clausen BE, Kaisho T, Tsujimura T, Terada N, Forster I, Akira S. Enhanced Th1 activity and development of chronic enterocolitis in mice devoid of Stat3 in macrophages and neutrophils. Immunity 1999; 10:39-49.

25 Bertrand V, Quere S, Guimbaud R et al. Effects of murine recombinant interleukin-10 on the inflammatory disease of rats transgenic for HLA-B27 and human beta 2-microglobulin. Eur Cytokine Netw 1998; 9:161-70.

26 Herfarth HH, Mohanty SP, Rath HC, Tonkonogy S, Sartor RB. Interleukin 10 suppresses experimental chronic, granulomatous inflammation induced by bacterial cell wall polymers. Gut 1996; 39:836-45.

27 Asseman C, Mauze S, Leach MW, Coffman RL, Powrie F. An essential role for interleukin 10 in the function of regulatory $\mathrm{T}$ cells that inhibit intestinal inflammation. J Exp Med 1999; 190:995-1004.

28 Cong Y, Weaver CT, Lazenby A, Elson CO. Bacterial-reactive $\mathrm{T}$ regulatory cells inhibit pathogenic immune responses to the enteric flora. J Immunol 2002; 169:6112-19.

29 Yamashita Y, Ono M, Takai T. Inhibitory and stimulatory functions of paired Ig-like receptor (PIR) family in RBL-2H3 cells. J Immunol 1998; 161:4042-7.

30 Ho LH, Uehara T, Chen CC, Kubagawa H, Cooper MD. Constitutive tyrosine phosphorylation of the inhibitory paired Ig-like receptor PIR-B. Proc Natl Acad Sci USA 1999; 96:15086-90. 